NBER WORKING PAPER SERIES

\title{
COVERED INTEREST PARITY, UNCOVERED INTEREST \\ PARITY, AND EXCHANGE RATE DYNAMICS
}

\author{
Jonathan Eaton \\ Stephen J. Turnovsky
}

Working Paper No. 984
NATIONAL BUREAU OF ECONOMIC RESEARCH 1050 Massachusetts Avenue
Cambridge MA 02138

September 1982

We wish to thank Gene M. Grossman for some helpful comments on this paper. The research reported here is part of the NBER's research program in International Studies. Any opinions expressed are those of the authors and not those of the National Bureau of Economic Research. 
NBER Working Paper \# 984

September 1982

Covered Interest Parity, Uncovered Interest Parity, and Exchange Rate Dynamics

\begin{abstract}
A number of macroeconomic models of open economies under flexible exchange rate assume a strong version of perfect capital mobility which implies that currency speculation commands no risk premium. If this assumption is dropped a number of important results no longer obtain. First, the exchange rate and interest rate cannot be in steady state unless both the government deficit and current account equal zero, not simply their sum, as would otherwise be the case. Second, even in steady state the domestic interest rate can deviate from the foreign interest rate by an amount which depends upon relative domestic asset supplies. Finally, introducing risk aversion on the part of speculators can reduce the response on impact of the exchange rate to changes in domestic asset supplies. In this sense rational speculators, if they are less risk averse than other agents, can destabilize exchange markets.
\end{abstract}

Jonathan Eaton Economic Growth Center Yale University Box 1987 Yale Station New Haven, CT 06520 (203) $436-8414$
Stephen J. Turnovsky Department of Economics University of Illinois 1206 South 6th Street Champaign, IL 61820 (217) 333-2354 
The advent of floating rates among the major currencies has led to the development of increasingly sophisticated models of open economies in which exchange rates are market determined. As was pointed out in the early work of Fleming (1962) and Mundell (1963) the degree of international capital mobility is crucial in determining the response of an economy to both monetary and fiscal actions. And while the FlemingMundell analysis is based on the traditional static short-run model, the importance of the degree of capital mobility applies to the long-run response as well.

Perhaps because capital does seem to be very mobile among the major industrial countries, the polar assumption of perfect capital mobility has received most attention. This assumption may be interpreted in two different ways, however. The first, weaker version is that bonds that are free of default risk domestically are also free of default risk abroad; in Aliber's (1973) terminology, there is no 'political' risk. When capital mobility of this degree obtains, foreign bonds on which forward cover has been obtained are perfect substitutes for domestic bonds and arbitrage brings the domestic interest rate (R) into equality with the foreign interest rate $\left(R^{*}\right)$ plus the forward premium on foreign exchange (F). Thus covered interest parity (CIP) obtains

$$
R=R^{*}+F
$$

where $R, R^{*}$ and $F$ are defined over the same time interval. In fact, empirical evidence suggests that among the major industrial nations, deviations from CIP are not significant; see, e.g., Aliber (1973), Frenkel and Levich $(1975,1977)$. 


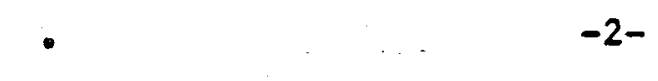

A stronger definition of capital mobility is one that adds to the criterion for the first the requirement that attitudes toward exchange risk be characterized by risk neutrality, either because there exists a sufficient number of risk neutral speculators, or because exchange risk is perfectly diversifiable. In this case, speculation will bring the forward premium on foreign exchange into equality with the expected rate of appreciation of the foreign currency; that is,

$$
F=(\dot{E} / E)^{e}
$$

where $E$ denotes the price of forelgn currency in terms of domestic currency, and where for any variable $x$, we define $\dot{x} \equiv d X / d t$ and $x^{e}$ denotes the expectation of $X$. Substituting (2) into (1) yields the condition

$$
R=R^{*}+(\dot{E} / E){ }^{e}
$$

a condition which is referred to as uncovered interest parity (UIP) and which requires both (I) and (2) to hold. I

However, the empirical evidence in support of (2) is not as strong as it is for (1). Levich (1978), Bilson (1978) and Hansen and Hodrick (1980) report some systematic deviations for several exchange rates over long perlods. These findings are consistent with financial models of foreign investment which suggest that risk aversion among rational, fully informed speculators will create a risk premium, thereby causing (2) to break down. Solnik (1973), Kourl (1976), Adler and Dumas (1977), Frankel (1979) and Eaton and Turnovsky (1981) derive various expressions for this premium based on expected utility maximization. 


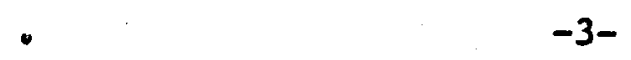

But despite the lack of theoretical justification for UIP and the empirical evidence against it, most wel1-known results about the behaviour of macroeconomic models with perfectly mobile capital require this stronger definition to apply. This paper develops a model of a small open economy under the more general assumption that the forward premium on foreign exchange is determined by risk averse speculative behavior. Capital is still perfectly mobile in the weaker sense that CIP obtains and a special case of our model is one in which the degree of risk aversion tends to zero, in which case UIP applies as well. We use this model to examine several propositions about the behaviour of a small open economy with a flexible exchange rate. These pertain to: the effects of changes in domestic asset supplies and foreign interest rate on the steady-state levels of the domestic interest rate and exchange rate; the effects of ongoing government deficits; and the dynamic behaviaur of the exchange rate between steady states. Our purpose in this analysis is twofold. First, we wish to illustrate the implications, some of them rather implausible, of assumptions that have been prominent In the literature. Secondly, we wish to examine the behaviour of the exchange rate under a more general specification that is consistent with a more plausible set of outcomes.

In Section I which follows we develop a dynamic model of an open economy in which the exchange rate, interest, rate, and forward premium are determined at each instant by money market and forward market equilibrium conditions, together with CIP. At any moment, the price of nontraded goods and asset supplies are predetermined, while we treat the foreign interest rate and price level as exogenous. Over time, 


\begin{abstract}
$-4-$
the price of nontraded goods adjusts gradually to the price of traded goods; the supplies of domestic assets change through the government deficit, while the balance of payments on current account determines the change in forelgn asset supplies. With risk averse speculative behaviour, exchange rate and price dynamics, on the one hand, become inherently linked with asset supply dynamics on the other. For the system as a whole, and the exchange rate and interest rate in particular, to be in steady state, all asset accumulation must cease and for this to occur, both the budget deficit and the balance of payments on current account must equal zero.

In the limiting case in which speculators are risk neutral, the conditions for the exchange rate and price level to attain steady state may be relaxed. For example, with a bond-financed government deficit, it is necessary only for the budget deficit and current account surplus to sum to zero. Thus the exchange rate and price level can be in steady state even if the govemment deficit is perpetually unbalanced, as long as it is offset by an appropriate imbalance on the current account. Thus when UIP obtains a small country can run a perpetual current account deficit without affecting its exchange rate or its interest rate. ${ }^{2}$ If, In addition to UIP, asset supplies do not affect the demand for money, the exchange rate and the price level evolve independently of the government deficit and the balance of payments on current account outside of steady state. In this case, the exchange rate and price level can be in steady state even if these two quantities do not sum to zero. ${ }^{3}$

These observations are of relevance to a number of recent studies of exchange rate dynamics (e.g., Dornbusch (1976), Gray and
\end{abstract}


Turnovsky (1979), and Wilson (1979)) who specify models of exchange rate and price dynamics in which domestic and foreign bond supplies play no explicit role. This exclusion is legitimate only under the strong assumption of UIP (an assumption all these authors make). Furthermore, Mundell's (1963) finding that under flexible rates a government deficit will not disturb the steady state exchange rate or interest rate (because its effect on the total bond supply is offset by the current account) also requires UIP to hold.

In Section II we examine the properties of the steady state 1tself. An important aspect of the income determination models of Mundell (1963) and Fleming (1962) and of the exchange rate dynamics of Dornbusch (1976) et al. is that, in steady state, the domestic interest rate equals the foreign interest rate and is independent of domestic asset supplies. 4 In addition, the steady state exchange rate and domestic price level are homogeneous of degree one in the domestic money supply. None of these results are preserved when speculators are risk averse. Thus, even if CIP obtains, the domestic interest rate can be affected by domestic policies in steady state, something that is not possible under UIP. Also, the exchange rate and domestic price level are homogeneous of degree one, and the interest rate homogeneous of degree zero, in the supplies of both domestic assets taken together, and not just money. 5 Sections III and IV examine the transition between steady states, a subject which has been receiving extensive treatment recently. In Section III we show that once-and-for-all proportional unannounced Increases in the supplies of money and domestic bonds introduced simultaneously can, on impact, cause either a smaller than, or greater than, 


\begin{abstract}
$-6-$
proportional response in the exchange rate. This result contrasts with the previous models in which, under similar assumptions but with UIP holding, the exchange rate necessarily 'overshoots' its steady state value. 6 The change in the exchange rate on impact can vary inversely with the degree of risk aversion. Our model thus suggests a sense in which speculation (or more properly, less risk averse speculation) destabilizes exchange rates; this is in the sense of increasing their short-run sensitivity to changes in domestic asset supplies. Finally, in Section IV we consider the dynamic effects of once-and-for-all unannounced changes in the money supply, achieved via open market operations.
\end{abstract}

I. A Dynamic Macro Model

We consider a small open economy in which private agents may hold as assets domestic money, domestic bonds, and foreign bonds, all of which, we assume, they regard as components of their net wealth. The first two assets are denominated in domestic currency, and the third in foreign currency. Thus at any moment, private nominal wealth $W$ is given by

$$
W=M+A^{d}+E B^{d}
$$

where $M$ denotes the supply of domestic money (which we assume is held only domestically), $A^{d}$ the number of dumestic bonds held domestically, $B^{d}$ the number of foreign bonds held domestically, $E$ is the spot rate measured as the price of a unit of foreign exchange in terms of domestic currency. 


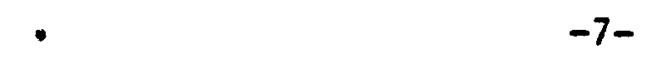

We assume that there is no perceived risk of default on domestic or foreign bonds so that CIP obtains 、

$$
\mathbf{R}=\mathbf{R} * \mathbf{F}
$$

Since our analysis is in continuous time, F measures the instantaneous rate of forward premium on foreign exchange and is defined formally by

$$
F(t) \equiv \lim _{h \rightarrow 0}\left(\frac{E^{f}(t, t+h)-E(t)}{h E(t)}\right)
$$

where $E^{f}(t, t+h)$ is the price at time $t$ of one unit of foreign exchange In period $t$ th. Since as the time unit $h \rightarrow 0$, the spot and forward rates must converge, $E(t)=E^{f}(t, t)$, in which case the limit in (6) may be expressed by the following partial derivative

$$
F(t)=E_{2}^{f}(t, t) / E^{f}(t, t)
$$

-

Since domestic and covered foreign bonds are perfect substitutes we shall assume that all domestic bonds are held domestically. Thus we let $A^{d}=A$, where $A$ denotes the total supply of domestic bonds. We allow $B^{d}$ to assume negative values when domestic agents issue liabilities denominated in foreign currency.

Individuals consume both traded and nontraded goods, which are Imperfect substitutes. Perfect goods arbitrage ensures that the prices of traded goods are determined by the law of one price. We assume that because of long term contracts, the prices of nontraded goods at any instant are fixed at $P$, say. An index of the domestic cost of living C is therefore 


$$
C=P^{\delta}\left(E P^{*}\right)^{1-\delta} \quad 0 \leqq \delta \leqq 1
$$

where $\delta$ denotes the share of nontraded goods in consumption and $P *$ is the exogenously given foreign price level (i.e., the foreign price of traded goods). For notational simplicity we set $P *=1$.

We assume a demand for money function of the form

$$
\frac{M}{C}=L(Y, R, H) \quad L_{Y} \geqq 0, L_{R} \leqq 0,0 \leqq L_{H} \leqq 1,
$$

where $\mathrm{Y}$ is real output and $\mathrm{H} \equiv \mathrm{W} / \mathrm{C}$ denotes real wealth. Note that we have deflated by $C$, reflecting the fact that real wealth depends upon the price of both traded and nontraded goods in accordance with their shares in consumption. Note that only $R$, the domestic interest rate is included in the money demand function. Elsewhere (Eaton and Turnovsky (1981)) we have derived optimal savings and portfolio behaviour for a single consumer in a two period model in which money provides utility via its transactions services. In this analysis, since domestic bonds and money are assumed to be equally risky, the division of assets denominated In domestic currency depends only upon the domestic interest rate. ${ }^{7}$

$$
\text { Together, equations (4), (5), (7) and (8) determine, at any }
$$

moment, equilibrium values of $C, R, F$, and $W$ as functions of $P, E, A, B^{d}$, $M$, and the exogenous foreign variables $R^{*}$ and $P *$.

We now turn to the dynamic equations of the system. First, consider forward market equilibrium. Participation in the forward market may be for two reasons, speculation and arbitrate. ${ }^{8}$ We assume that the real demand for speculative foreign exchange forward, denoted by $\mathrm{J}$, is an increasing function of the expected rate of return on speculation, 


$$
-9-
$$

given by the difference between the expected rate of depreciation of the domestic currency $(\dot{E} / E)^{e}$ and the forward premium $F$. We shall assume expectations are realized on average. Since we suppress stochastic elements in our model, except for unanticipated once-and-for-all changes in asset supplies, this is equivalent to assuming perfect foresight. Thus $(\dot{E} / E)^{e}=\dot{E} / E$ except at the moment when asset supplies change. 9 Forward market equilibrium requires that $\mathrm{J}$ equal the supply of foreign exchange forward for arbitrage; i.e., that which is sold to cover domestic holdings of foreign bonds:

$$
\frac{E B^{d}}{C}=J\left(\frac{\dot{E}}{E}-F\right) \quad J^{\prime} \geq 0 .
$$

Such a specification follows from financial micro models of the forward market; see, for example, Kouri (1976), Adler and Dumas (1977), and Eaton and Turnovsky (1981). Frankel (1979) has emphasized that this specification relies on the assumption that domestic government debt constitutes a component of private national wealth, an assumption we make here. As shown by previous authors, $J$ embodies attitudes to risk taking. In particular, $J$ ' varies inversely with the degree of risk aversion, with $J^{\prime} \rightarrow \infty$ in the Iimiting case of risk neutrality; when CIP obtains. By appropriate choice of units, the steady-state price of nontraded goods can be equated to the domestic price of traded goods. We assume that the price of nontraded goods is determined by Iong term contracts, so that the nontraded goods price cannot jump instantaneously to its equilibrium level, but can adjust only continuously over time, as contracts expire. When the average price of non-traded goods exceeds 


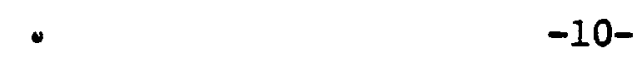

its normal level, we assume that their output exceeds their steady state supply and conversely. Consequently, we specify a relationship for the supply of real output as

$$
Y-\tilde{Y}=Z(E / P) \quad Z \prime>0, Z(1)=0
$$

where $\bar{Y}$ denotes the steady state value of $Y$, which we treat as exogenous. We also assume that when $Y>\tilde{Y}$ the price of non-traded goods is revised upwards and conversely. This adjustment is specified by the relationship 10

$$
\dot{P}=G(E / P) \quad G^{\prime}>0, G(1)=0 \text {. }
$$

The rate of change in the supply of domestic assets is determined by the government budget constraint

$$
\dot{\mathrm{M}}+\dot{\mathrm{A}}=P G_{\mathrm{d}}+E G_{\mathrm{m}}-\mathrm{T}+\mathrm{RA} \equiv \mathrm{g}
$$

where $G_{d}$ and $G_{m}$ represent real government expenditures on nontraded and traded goods, respectively, and $\mathrm{T}$ denotes nominal tax revenues. The rate of change in the domestic holdings of foreign assets is equal to the balance of payments on current account

$$
E \dot{B}^{d}=E X(\cdot)-E G_{m}+R * E B^{d} \equiv b
$$

where $X(\cdot)$ denotes real net exports of the private sector.

Together with an assumption about how the government finances its expenditures, equations (9), (10), (11), (12), and (13) determine the evolution of E, P, Y, A, M, and $B^{d}$. From the description of the system it might appear that the spot rate $E$ is constrained always to move continuously. This is not so. Because of the assumption of perfect foresight 
embodied in (9), the dynamics will generally involve (at least) one unstable root. Following the rational expectations methodology, this root may be eliminated by allowing the exchange rate to undergo an endogenously determined initial jump at points where the system is subject to an exogenous disturbance. Simple examples of this are given in Sections III and IV below.

Define total nominal bond holdings $B$ as

$$
B \equiv A+E B^{d} \text {. }
$$

Adding (12) and (13) and using the CIP condition (5), we obtain

$$
\dot{\mathrm{M}}+\dot{\mathrm{B}}=\mathrm{PG} \mathrm{d}_{\mathrm{d}}-\mathrm{T}+\mathrm{EX}+\mathrm{RB}+(\dot{\mathrm{E}} / \mathrm{E}-\mathrm{F}) \mathrm{EB} \mathrm{d}^{\mathrm{d}}
$$

From this equation it is evident that in general the evolution of the system depends upon the breakdown of $B$ between domestic and foreign bonds. Thus, for example, if $\dot{M}=0$ (the deficit is bond-financed), $E$, $P$ and $B$ cannot assume their steady state values unless $\dot{B}^{d}=\dot{A}=0$; that is, unless both the government deficit $(g)$ and the balance of payments on current account (b) are zero. And the same applies in the case of money financing.

Consider, however, the limiting case in which $J^{*}(\cdot) \rightarrow \infty$, i.e., the speculative demand for foreign exchange forward becomes infinitely elastic. In order for the speculative demand to remain bounded, (2) must hold. In this case (5) and (9) reduce to the UIP condition (3), so that (14) becomes

$$
\dot{\mathrm{M}}+\dot{\mathrm{B}}=\mathrm{PG}_{\mathrm{d}}-\mathrm{T}+\mathrm{EX}+\mathrm{RB}
$$


Writing (4) as

$$
\mathrm{H}=(\mathrm{M}+\mathrm{B}) / \mathrm{C}
$$

equations (4), (7), (3), (8), (10), (11), (14') constitute a dynamic system in which $A$ and $B^{d}$ do not appear (assuming of course that $A$ and $B^{d}$ do not enter separately in the specifications of $G_{d}, G_{m}, T$, or $X$ ). If the government deficitt is bond-financed $\dot{M}=0$. The dynamics depend only upon the sum of the government deficit and the current account deficit $(g+b)$ and not the separate components. Steady state now only requires that $\dot{B}=\dot{E}=\dot{P}=0$. The government may sustain a deficit in steady state as long as it is offset by a current account deficit of equal size, since the steady state requirement $\dot{B}=0$ is equivalent to $\dot{A}=-E \dot{B}$. With money financing, both components must be zero.

A special case widely adopted in the literature, and therefore of importance, arises if the demand for money is assumed to be independent of real wealth $\mathrm{H}$. Consider first the limiting assumption of risk neutral speculation. If the government deficit is bond-financed, the dynamics of $P$ and $E$ become independent of $g+b$ and these variables can attain steady state equilibrium with wealth, in the form of bonds, being accumulated indefinitely. ${ }^{11}$ With a money-financed deficit, steady state for $E$ and $P$ requires only that the government deficit be zero; the current account balance can be non-zero, with domestic residents continually accumulating (or decumulating) foreign bonds. In the general case where $\mathrm{J}^{\prime}$ is finite, no variable can be in steady state unless $g=b=0$. However, under bond financing $E$ and $P$ can attain steady 
. $-13-$

state with only $b=0$, provided one imposes the additional restriction that net exports be independent of $\mathrm{H}^{12}$

In formulating dynamic macro models such as the one above, it is often convenient to specify real savings behaviour (or asset accumulation) directly. Thus, if one postulates

$$
\frac{E \dot{B}^{d}+\dot{M}+\dot{A}}{C}=S(\cdot)
$$

it follows from (4), (13), and (15) that the rate of net capital inflow $E \dot{B}^{\mathrm{d}}$ can be derived as

$$
\begin{aligned}
E \dot{B}^{d} & =\operatorname{cs}(\cdot)-(\dot{M}+\dot{A}) \\
& =\operatorname{cs}(\cdot)-\left[P G_{d}+E G_{m}\right]+T-R A .
\end{aligned}
$$

By comparing (13) and $(16)$ it is clear that $S(\cdot), X(\cdot)$, and the government financing decision cannot be specified independently.

- These observations about the appropriate specification of dynamic models under perfect capital mobility have important implications for various models appearing in the literature. First, the model of exchange rate dynamics introduced by Dornbusch (1976) and studied by other authors ignores the balance of payments and savings behaviour in analyzing the dynamics of the exchange rate. This is possible only because they assume UIP and that there are no asset supply effects on money demand. Under the less restrictive condition of CIP, however, the dynamic adjustment of the exchange rate, on the one hand, and asset accumulation, on the other, are jointly determined, even in the absence of wealth effects In the demand for money. 
$-14-$

Second, a well known result of Mundell (1968) is that a government deficit has no effect on the steady state of a small open economy 'under conditions of perfect capital mobility and flexible exchange rates. This is certainly true under the conditions of UIP when any change in the deficit will be offset by a change in the current account deficit, leaving the system unchanged. However, it is not generally true under CIP, when indeed steady state requires the deficit to be zero.

II. Steady State Properties

Models of exchange rate determination based on the assumption of UIP and the absence of an ongoing inflation yield the following steady state relationship

$$
\overrightarrow{\mathbf{R}}=\mathbf{R}^{*}
$$

where is used to denote the steady state value of a variable. Thus the domestic interest rate is completely tied to the world rate, from which we immediately infer:

(1) Changes in the foreign interest rate yield equal changes in the domestic interest rate;

(ii) the domestic interest rate is independent of the supply of domestic money or domestic bonds.

Other steady state properties depend upon the policy specification and the dynamic system so generated. If one adopts the frequently postulated savings function ${ }^{13}$. 
$-15-$

$$
S=\phi\left(\bar{H}\left(Y, R^{*}\right)-H, \tilde{Y}\right)
$$

Where $\bar{H}$ is some long-run desired level of real wealth, the steady state monetary equilibrium relationship becomes

$$
\frac{M}{E}=L\left(\tilde{Y}, R^{*}, \bar{H}\left(\tilde{Y}, R^{*}\right)\right)
$$

From this equation, two further propositions follow:

(iii) A given change in the domestic money supply leads to a proportionate change in the exchange rate;

(iv) the exchange rate is independent of the supply of domestic bonds.

None of properties (i)-(iv) characterizes the steady state of the model presented in Section $I$, except in the limiting case when the speculative demand for foreign exchange forward is perfectly elastic. ${ }^{14}$

We adopt the savings function (18) and assume, for simplicity and without essential loss of generality, that $\overline{\mathrm{H}}$ is exogenous and independent of the interest rate. The steady state of the model presented in Section $I$ is attained when $\dot{E}=\dot{P}=\dot{A}=\dot{M}=\dot{B}^{d}=0$. Imposing these conditions yields the equations

$$
\begin{gathered}
\overline{\mathrm{B}}=\frac{\dot{\mathrm{M}}+\dot{\mathrm{A}}}{\tilde{\mathrm{E}}}+\tilde{\mathrm{B}}^{\mathrm{d}} \\
\tilde{\mathrm{R}}=\mathrm{R}^{*}+\tilde{\mathrm{F}} \\
\frac{\tilde{\mathrm{M}}}{\overline{\mathrm{E}}}=\mathrm{L}(\tilde{\mathrm{Y}}, \tilde{\mathrm{R}}, \overline{\mathrm{H}}) \\
\tilde{\mathrm{B}}=\mathrm{J}(-\tilde{\mathrm{F}})
\end{gathered}
$$


$-16-$

$$
\tilde{E}\left(G_{d}+G_{m}\right)-\tilde{T}+\tilde{R} \tilde{A}=0
$$

Given $\overline{\mathrm{H}}$, these five equations involve the seven variables, $\tilde{M}, \tilde{A}, \tilde{B}^{\mathrm{d}}, \tilde{\mathrm{E}}$, $\tilde{R}, \tilde{F}, \tilde{T}$. We shall assume initially that the monetary authorities peg $M=\overline{M i}$ and $A=\bar{A}$, continuously adjusting $T$ to balance the budget.

Thus $\bar{M}, \bar{A}$, along with $R^{*}$, may be treated as exogenous parameters. Totally differentiating the system with respect to these variables we obtain the following effects on the domestic interest rate $\tilde{R}$

$$
\begin{gathered}
\frac{d \tilde{R}}{d \bar{M}}=-\frac{\bar{A}}{\tilde{E} \Delta}<0 \\
\frac{d \tilde{R}}{d \bar{A}}=\frac{\bar{M}}{\tilde{E} \Delta}>0 \\
\frac{d \tilde{R}}{d R^{*}}=\frac{J^{\prime} \bar{M}}{\Delta} \begin{cases}> & 0 \\
< & 1\end{cases}
\end{gathered}
$$

where $\Delta \equiv J^{\prime} \bar{M}-L_{R}(\bar{M}+\bar{A})>0$.

Thus a once-and-for-all increase in the domestic money supply reduces the steady-state domestic interest rate, while an increase in the domestic supply of bonds increases 1t. An increase in the foreign interest rate leads to a reduction in the forward premium, causing the domestic interest rate to rise by a smaller amount. In the limiting case when $\mathrm{J}^{\prime} \rightarrow \infty$, the response becomes proportional and in this extreme case changes in $\bar{M}$ and $\bar{A}$ have no effect on $R$. Thus, unless speculators are risk neutral or perceive no exchange risk, the domestic interest rate is not totally determined by the interest rate abroad and responds to domestic asset supplies in the manner indicated. 
Multiplying (21a) by $\bar{M}$ and (21b) by $\bar{A}$ and summing yields an expression equal to zero. Thus an increase in the domestic money supply accompanied by a proportional increase in the domestic bond supply is neutral in its effect on the steady state domestic interest 玉ate.

Changes in $\bar{M}$ and $\bar{A}$ have the following proportional effects on the steady state spot rate $\mathrm{E}$

$$
\begin{aligned}
& \frac{\mathrm{d} \tilde{\bar{E}}}{\underline{d \overline{\bar{M}}}} \cdot \frac{\overline{\bar{M}}}{\overline{\bar{E}}}=\frac{\overline{\bar{M}}\left(J^{\prime}-L_{R}\right)}{\Delta}\left\{\begin{array}{l}
>0 \\
<1
\end{array}\right. \\
& \frac{d \tilde{E}}{\overline{d \bar{A}}} \cdot \frac{\overline{\bar{A}}}{\tilde{E}}=-\frac{\overline{\bar{A}} L_{R}}{\bar{d}}\left\{\begin{array}{l}
>0 \\
<1
\end{array} .\right.
\end{aligned}
$$

Both elasticities are positive and less than one, while summing to unity. Thus, contrary to propostitions (iii) and (iv), an Increase in the money supply leads to a less than proportional increase in the exchange rate, While the supply of domestic bonds also affects the exchange rate. Proportional increases in the supplies of the two nominal assets together leads to proportional increases in the exchange rate and the domestic price level. As $J^{\prime} \rightarrow \infty,(22 a)$ Eends to unity and (22b) tends to zero. Thus only in this liafting case do propositions (ii1) and (iv) hold. Tiseal policy involves changing $\bar{A}$. A well-known proposition of Mundell (1963) and Fleming (1962) is that under flexible rates and perfect capital mobility fiscal policy has no effect on the steady state of a small open economy. It is evident from our analysis that again for this result to apply, perfect capital mobillty must be interpreted to mean that UIP obtains, i.e., that foreign exchange speculation requires \#० risk premium. 


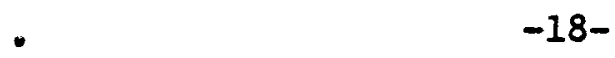

The same general characteristics of the steady state described by $(20 a)-(20 e)$ obtain under alternative policy specifications. If, for example, tax receipts are held at a constant real level, say $\tau$, and the government finances its deficit with bonds, the steady state relations (20a)-(20e) will continue to determine the steady state values of $\bar{B}$, $\tilde{\mathrm{R}}, \tilde{\mathrm{F}}, \tilde{\mathrm{E}}$, and $\tilde{\mathrm{A}}$. Now, however, (20e) requires the stock of domestic bonds to adjust in proportion to the exchange rate, since $\tilde{T}=\tilde{E} \tau$. Under UIP propositions (i) and (iv) still obtain but if UIP does not hold these propositions will be violated as before. The responses of $\tilde{R}$ and $\tilde{E}$ to changes in $R^{*}$ and $\bar{M}$ can be calculated (A is now endogenous) and will generally differ from the expressions given in (21), (22) above because of the difference in policy specification.

We conclude this discussion with a further comment on (2Ic), which asserts that an increase in $R^{*}$ leads to a fall in the forward premium, thereby leading to a smaller rise in the domestic interest rate. This result turns out to depend upon the specification of the savings function and under an alternative specification the domestic interest rate may actually increase by more. To illustrate this, suppose that instead of specifying a savings function as we have done, we specify a net export function

$$
X=X(E / P, Y), \partial X / \partial(E / P)>0, \partial X / \partial Y \leqq 0,
$$

The steady state of the system now consists of $(20 a)-(20 e)$, together with the steady state of (13)

$$
X(1, \tilde{Y})-G_{m}+R * \tilde{B}^{d}=0
$$


Since in steady state $\tilde{E}=\tilde{P}$, and $Y=\tilde{Y}, X$ is now fixed. $\tilde{H}$ is now endogenous and, given $\bar{A}$ and $\bar{M}$, is determined together with $\tilde{B}, \tilde{E}, \tilde{R}, \tilde{F}$, and $\tilde{T}$. Consider an increase in $R^{*}$. Since in steady state $X-G_{m}$ is independent of $R^{*}$ it follows from (20f) that in order for the balance of payments on current account to remain in equilibrium, $\tilde{B}$ must fall. If $\tilde{B}^{d}$ falls, forward market equilibrium condition (20d) requires the forward premium to rise, in which case the CIP condition (20b) implies a larger increase in the domestic interest rate than the rise in the foreign rate. III. Exchange Rate Dynamics: Proportional Increases in Money and
Domestic Bond Supplies

We now consider an economy in which steady state is disturbed by once-and-for-all increases in the money supply and domestic bond supply of equal proportion and examine the behaviour of the exchange rate during its transition to the new steady state. For convenience, we assume a log-linear version of the model developed in Section I. Other simplifications are introduced not only to expedite the dynamic analysis, but also to make our results as comparable as possible with the existing literature.

Following, for example, Driskill (1980), we take the followIng log-linear approximation to wealth

$$
\mathbf{h}=\mu_{1} a+\mu_{2}\left(e+b^{d}\right)+\left(1-\mu_{1}-\mu_{2}\right) m-c \equiv w-c
$$

where $\mu_{1}$ is the share of domestic bonds in domestic wealth and $\mu_{2}$ is the share of foreign bonds. ${ }^{15}$ We denote $r \equiv R-\tilde{R}_{0}, f \equiv F-\tilde{F}_{0}$ and for all other variables let $x \equiv \ln x-\ln \bar{x}_{0}$, where for any variable 
$\tilde{X}_{0}$ denotes the value of $X$ in the initial steady state. Thus $x$ is the percentage deviation in $\mathrm{X}$ from its initial steady state value.

Assuming that the foreign interest rate remains unchanged at $R^{*}$, the interest rate parity condition (expressed in deviation form) is

$$
r=f
$$

while the price index now becomes

$$
c=\delta p+(1-\delta) e .
$$

A log linear approximation to the supply function (10) is

$$
y=p(e-p) \quad p \geqq 0
$$

and a similar approximation to money market equilibrium is given by

$$
m-c=-\alpha_{1} r+\alpha_{2} w+\alpha_{3} y \quad \alpha_{1} \geqq 0
$$

Imposing the assumption of perfect foresight (except at points where asset supplies change), the log-linear approximation to the condition for forward market equilibrium becomes

$$
e+b^{d}-c=\gamma(\dot{e}-f) \quad \gamma \geq 0
$$

where $\gamma$ is the elasticity of speculative demand for foreign exchange forward with respect to the risk premium. $\gamma$ varies inversely with the degree of risk aversion with $\gamma \rightarrow \infty$ as risk neutrality is approached. 16 The adjustment of prices is specified by ${ }^{17}$

$$
\dot{p}=\theta(e-p) \quad \theta>0 \text {. }
$$




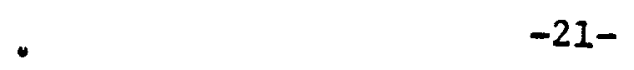

Since our analysis treats the nominal supplies of money and domestic bonds as fixed everywhere except at one instant, savings must take the form of accumulating foreign bonds. Assuming that interest rates do not affect desired wealth, we approximate the asset accumulation function (16) by

$$
\dot{\mathrm{b}}^{\mathrm{d}}=-\sigma_{1} \mathrm{~h}+\sigma_{2} \mathrm{y} \quad \sigma_{1} \geqq 0, \sigma_{2} \geqq 0 \text {. }
$$

This expression can also be interpreted as a log linear approximation to the current account equation.

Equations (23) to (30) constitute a complete dynamic system. Equations (23) through (27) determine at any moment values of $h, c, r$, $y$ and $f$ as functions of $e, p$. and $b^{f}$, whose dynamic behaviour is described by equations (28) through (30).

For the special case in which $\alpha_{2}=0$ (zero wealth effects in the demand for money) $p=0$ (fixed real output) and $\gamma \rightarrow \infty$ (currency speculation requires no risk premium) the model outlined in equations (23) to (30) reduces in essence to the one examined by Dornbusch (1976), Gray and Turnovsky (1979), and Wilson (1979). As we mentioned in Section $I$, when $\gamma \rightarrow \infty$, exchange rate dynamics are independent of $B^{d}$ and A. For this reason these earlier studies did not require any assumptions about the bond-financed component of the government deficit or about savlings behaviour.

Dornbusch et al. consider the effects of a once-and-for-all change in the money supply on the path of the exchange rate and price level. As we pointed out in Section II, in the special case they consider, the steady state effect of such a change is a proportional change 
In the exchange rate and the price level, with the domestic interest rate remaining unchanged. To maintain this long-run neutrality in our more general model, the change in the money supply must be accompanied by a proportional change in the supply of domestic bonds. This policy is a once-and-for-all transfer of money and bonds and is considered in this section.

Consider an initial steady state in which all variables in equations (23) through (30) are zero (i.e., $\ln x=\ln x_{0}$, etc.) and assume that the supplies of money and domestic bonds are both increased once-and-for-all by $\bar{m}$ percent. ${ }^{18}$ In the new steady state, $\tilde{e}=\tilde{p}=\tilde{c}=\bar{m}$, while all other variables return to their initial (zero) levels. Solving equations (23) through (27) for h, c, r, f, and $y$, and substituting the resulting expressions into (28) through (30) allows us to describe the equations as a third-order system of differential equations in $e, p$, and $b^{d}$

$$
\begin{aligned}
& \left(\begin{array}{l}
\dot{e} \\
\dot{p} \\
\dot{b}
\end{array}\right)=\left(\begin{array}{ccc}
a_{1} & a_{2} & a_{3} \\
\theta & -\theta & 0 \\
c_{1} & c_{2} & c_{3}
\end{array}\right)\left(\begin{array}{l}
e \\
p \\
b
\end{array}\right)+\left(\begin{array}{l}
a_{0} \\
0 \\
c_{0}
\end{array}\right) \\
& a_{1} \equiv \frac{\delta}{\gamma}+\frac{\alpha_{3} p+\alpha_{2} \mu_{2}+\left(1-\alpha_{2}\right)(1-\delta)}{\alpha_{1}} ; a_{2}=\frac{-\delta}{\gamma}-\frac{\alpha_{3} \rho-\left(1-\alpha_{2}\right) \delta}{\alpha_{1}} ; \\
& a_{3} \equiv \frac{1}{\gamma}+\frac{\alpha_{2} \mu_{2}}{\alpha_{1}} ; a_{0} \equiv \frac{\alpha_{2}\left(1-\mu_{2}\right)-1}{\alpha_{1}}-\frac{m}{c_{1}} \equiv \sigma_{1}\left(1-\delta-\mu_{2}\right)+\sigma_{2} \rho ; c_{2} \equiv \sigma_{1} \delta-\sigma_{2} \rho \\
& c_{3} \equiv-\sigma_{1} \mu_{2} ; c_{0} \equiv \sigma_{1}\left(\mu_{2}-1\right) \bar{m}
\end{aligned}
$$




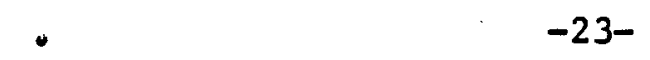

\section{Letting}

$$
x_{1} \equiv e-\ddot{e}, x_{2} \equiv p-\bar{p}
$$

where $\tilde{\mathrm{e}}=\tilde{\mathrm{p}}=\overline{\mathrm{m}}$, we may write the nonhomogeneous system (31) in homogeneous form

$$
\left(\begin{array}{l}
\dot{x}_{1} \\
\dot{x}_{2} \\
\dot{b}
\end{array}\right)=\left(\begin{array}{lll}
a_{1} & a_{2} & a_{3} \\
\theta & -\theta & 0 \\
c_{1} & c_{2} & c_{3}
\end{array}\right)\left(\begin{array}{l}
x_{1} \\
x_{2} \\
b
\end{array}\right)
$$

The solution to the equation is

$$
\begin{aligned}
& e(t)=\vec{m}+A_{1} \exp \left(\lambda_{1} t\right)+A_{2} \exp \left(\lambda_{2} t\right)+A_{3} \exp \left(\lambda_{3} t\right) \\
& p(t)=\vec{m}+B_{1} \exp \left(\lambda_{1} t\right)+B_{2} \exp \left(\lambda_{2} t\right)+B_{3} \exp \left(\lambda_{3} t\right) \\
& b^{d}(t)=c_{1} \exp \left(\lambda_{1} t\right)+c_{2} \exp \left(\lambda_{2} t\right)+c_{3} \exp \left(\lambda_{3} t\right)
\end{aligned}
$$

where $\lambda_{1}, \lambda_{2}$, and $\lambda_{3}$ are the solutions to the characteristic equation of $\left(31^{\prime}\right)$

$$
\begin{gathered}
\lambda^{3}-\left(a_{1}+c_{3}-\theta\right) \lambda^{2}-\left[\theta\left(a_{1}+a_{2}+c_{3}\right)-a_{1} c_{3}+c_{1} a_{3}\right] \lambda \\
-\theta\left[\left(c_{1}+c_{2}\right) a_{3}-\left(a_{1}+a_{2}\right) c_{3}\right]=0
\end{gathered}
$$

and where given the arbitrary constant $A_{1}, A_{2}$, and $A_{3}$, the remaining constants $B_{i}, C_{i}, i=1,2,3$ are determined by the relationships

$$
\left[\begin{array}{l}
B_{i} \\
c_{i}
\end{array}\right]=\left[\begin{array}{ll}
a_{2} & a_{3} \\
c_{2} & c_{3}-\lambda_{i}
\end{array}\right]\left[\begin{array}{c}
\lambda_{i}-a_{i} \\
-c_{i}
\end{array}\right] A_{i} \quad i=1,2,3
$$


The constant term in (33) can be shown from the definitions of $a_{i}$ and $c_{1}$ to be unambiguously negative, implying that the product of the roots, $\lambda_{1} \lambda_{2} \lambda_{3}>0.19$ Thus (31) has either one or three positive eigenvalues. Moreover, the coefficient of $\lambda$ in (33), which equals $-\left(\lambda_{1} \lambda_{2}+\lambda_{2} \lambda_{3}+\lambda_{3} \lambda_{1}\right)$ is almost certainly positive, in which case some of the roots must be negative, so that in fact there can be only one unstable root. A sufficient, but by no means necessary, condition for this to be so is $\mu_{2}<\alpha_{2} / \alpha_{1}$, imposing an upper limit on the fraction of foreign bonds held. We shall treat the case of a single unstable root, denoted by $\lambda_{3}$, as the normal one and impose the requirement that the system converge to its steady state, 1.e.,

$$
\lim e(t)=\bar{e} ; \lim p(t)=\tilde{p} ; \lim b^{d}(t)=0 .
$$

Convergence then requires that the coefficients of the unstable root equal zero. 20 Thus $A_{3}=0$ and via, (34), $B_{3}=C_{3}=0$.

In keeping with the literature on exchange rate dynamics, we assume that, while discontinuous jumps in the exchange rate are possible, the price of nontraded goods is constrained to move continuously. The fact that the exchange rate is determined by virtually continuous tradIng in an auction market, while the prices of nontraded goods are determined mainly by a large number of longer-term contracts, makes this assumption plausible. This constraint implies the initial condition

$$
p(0)=0 ; \text { or } B_{1}+B_{2}=-\bar{m}
$$

Similarly, the requirement that foreign assets can be acquired only continuously over time requires that the asset disturbance cannot move $b^{d}$ from its initial level on impact, so 


$$
b^{d}(0)=0 ; \text { or } c_{1}+c_{2}=0 \text {. }
$$

Equations (35) and (36), together with the four equations contained in (34) for $i=1,2$, determine the six coefficients of the stable roots, namely, $A_{1}, B_{i}, C_{i}, i=1,2$.

Assuming stability, consider now the value of the exchange rate immediately after the increase in the supplies of money and bonds takes place at $t=0$. This value, denoted by $e(0+)$, is given by $A_{1}+A_{2}+\bar{m}$. Thus the exchange rate overshoots or undershoots its new steady state level, according as the values of $A_{1}$ and $A_{2}$, derived from (34)-(36) yield $A_{1}+A_{2} \gtrless 0$.

For the general case, an explicit analytical expression for e(ot) proves to be rather intractable, and because of the complicated nature of the calcuiations, not particularly illuminating. 21 However, a good indication of the likely response of the exchange rate to proportional increases in domestic assets can be obtained by focusing on two polar cases; one in which asset accumulation proceeds very slowly, another in which assets adjust very rapidly.

\section{Slow Asset Adjustment}

The first case we consider is one where the savings adjustment to the shock is very slow relative to the price level adjustment. We consider the limiting case in which $\sigma_{1}=\sigma_{2}=0$. Portfolio adjustment costs may provide one justification forexamining this limiting case in our example. The reason is that the steady state level of $b^{d}$ is unaffected by the shock we consider. If price adjustment is relatively rapid, wealth holders may not find varying their holdings of $b^{d}$ during the transition to be worthwhile. 
$-26-$

In considering this special case, then, we may set $b^{d}(t)=0$ for all t. Defining $x_{1}$ and $x_{2}$ as before, we can write the system in the homogeneous second order form

$$
\left[\begin{array}{l}
\dot{x}_{1} \\
\dot{x}_{2}
\end{array}\right]=\left[\begin{array}{ll}
a_{1} & a_{2} \\
\theta & -\theta
\end{array}\right]\left[\begin{array}{l}
x_{1} \\
x_{2}
\end{array}\right]
$$

where $a_{0}, a_{1}$, and $a_{2}$ are as defined above.

The solution to this equation is

$$
\begin{gathered}
e(t)=\bar{m}+A_{1} \exp \left(\lambda_{1} t\right)+A_{2} \exp \left(\lambda_{2} t\right) \\
p(t)=\bar{m}+A_{1} \frac{\lambda_{1}-a_{1}}{a_{2}} \exp \left(\lambda_{1} t\right)+A_{2} \frac{\lambda_{2}-a_{1}}{a_{2}} \exp \left(\lambda_{2} t\right)
\end{gathered}
$$

where $\lambda_{1}, \lambda_{2}$, are the solutions to the characteristic equation of (37)

$$
\lambda^{2}+\left(\theta-a_{1}\right) \lambda-\theta\left(a_{1}+a_{2}\right)=0
$$

From the definitions of $a_{1}$ and $a_{2}$ we observe

$$
a_{1}+a_{2}=\frac{1-\alpha_{2}+\alpha_{2} \mu_{2}}{\alpha_{1}}>0
$$

If and only if $\alpha_{2}<1 /\left(1-\mu_{2}\right)$. If the country is a creditor, this conditIon will certainly be met if the wealth elasticity of the demand for money does not exceed unity, a condition which seems reasonable to impose. Thus (40) implies that the system (37) has one negative and one positive root, which we shall identify as $\lambda_{1}<0, \lambda_{2}>0$, respectively. 22 
To complete the solution requires the determination of the arbitrary constants $A_{1}, A_{2}$. Imposing the requirement that the system converges to its steady state,

$$
\lim _{t \rightarrow \infty} e(t)=\tilde{e} ; \quad \lim _{t \rightarrow \infty} p(t)=\tilde{p}
$$

For this to be so the coefficient of the unstable root $A_{2}=0$. The other constant is obtained from the condition that p start from its initial steady state value of zero, i.e., that

$$
p(0)=A_{1} \frac{\lambda_{1}-a_{1}}{a_{2}}+\bar{m}=0,
$$

This condition in turn implies that

$$
A_{1}=\frac{a_{2}}{a_{1}-\lambda_{1}} \bar{m}
$$

Substituting the values for $A_{1}, A_{2}$ into (38a), (38b), recalling that $\tilde{e}=\tilde{p}=\bar{m}$, yields the following solutions for the exchange rate and price of nontraded goods

$$
\begin{gathered}
e(t)=\left(1+\frac{a_{2}}{a_{1}-\lambda_{1}} \exp \left(\lambda_{1} t\right)\right) \bar{m} \\
p(t)=\left[1-\exp \left(\lambda_{1} t\right)\right] \bar{m} .
\end{gathered}
$$

Consider now the value of the exchange rate immediately after the increase in the money and bond supplies at $t=0$. This value, denoted by $e(o+)$ is given by

$$
e(o+)=\left(1+\frac{a_{2}}{a_{1}-\lambda_{1}}\right) \bar{m} \text {. }
$$




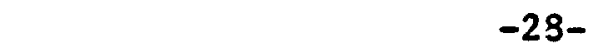

It can be established from (39) that the smaller root $\lambda_{1}$ satisfies

$$
\lambda_{1}<a_{1}-\theta<a_{1}
$$

so that $e(o+)>\bar{e}(=\bar{m})$ as $a_{2} \geqslant 0$ or, equivalently, as

$$
\gamma\left[\left(1-\alpha_{2}\right) \delta-\alpha_{3} \rho\right]-\alpha_{1} \delta \geqslant 0 .
$$

The exchange rate overshoots or undershoots its new steady state value as $\mathrm{e}(\mathrm{o}) \gtrless \overline{\mathrm{m}}$ and (44) provides a simple criterion for determining which of these two cases occurs. In the limiting case of the Dornbusch model, $\alpha_{2}=0, \rho=0$, and $\gamma \rightarrow \infty$, ensuring that overshooting takes place. Dornbusch also considers the case in which income is endogenous and shows how the income effect in the demand for money can lead to undershooting. But even when income is fixed $(\rho=0)$, however, the presence of imperfectly elastic speculation can lead to undershooting. Given that speculators are risk averse, undershooting is more likely to occur when the wealth and interest elasticities of money demand are large. 23 Furthermore, differentiating e(ot) with respect to $\gamma$ indicates that as Iong as $\alpha_{2}<1$, de(ot)/dy>0; an increase in the elasticity of speculation raises the impact effect on the exchange rate of a change in nominal asset supplies.

The phenomenon of overshooting has been cited as a reason for the observed volatility of exchange rates; changes in asset supplies create movements in exchange rates that exaggerate the implications of these changes for steady state. According to this interpretation, speculation acts to destabilize the foreign exchange market. As risk aversion on the part of speculators falls, making the supply of 


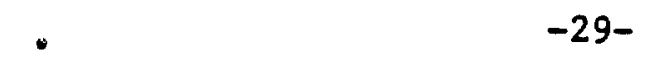

speculative funds more elastic, the exchange rate reacts more sharply to changes in asset supplies. 24

To understand this result observe that since the prices of nontraded goods are sticky, changes in nominal asset supplies constitute, on impact, changes in real asset supplies. The exchange rate and interest rate must adjust to restore asset market equilibrium. An increase in the nominal supplies of money and domestic bonds increase both the supply of and demand for money, the second via a wealth effect. Taking the likely case $\alpha_{2}<1$, the net impact on the money market is to create an excess supply. To maintain equilibrium in the money market during the adjustment period requires a lower domestic interest rate, which in turn requires a lower forward premium on foreign exchange, f. When speculation is perfectly elastic, $f=\dot{e}$. In this case, a lower domestic interest rate requires a continuous appreciation $(\dot{e}<0)$ during the adjustment period. If the exchange rate is to appreciate to its new, higher, steady state value it must initially depreciate to a value above $\overline{\mathrm{e}}$; that is, the exchange rate must overshoot.

When speculation is less than perfectly elastic, $(\gamma<\infty)$, however, an exchange rate depreciation also impinges on forward market equilibrium by revaluing domestic holdings of foreign bonds. This revaluation creates an excess supply of foreign exchange forward which acts to bid down the forward premium on foreign exchange $f$. If the drop in $f$ required to restore forward market equilibrium excees the drop required to restore money market equilibrium, then a continuous depreciation $(\dot{e}>0)$ is needed to maintain equilibrium in both markets. For this continuous depreciation to converge to the new steady state exchange rate, 
the depreciation on impact must be less than the steady state depreciation; that is, undershooting of the exchange rate must occur.

III.2. Rapid Asset Adjustment

The second case we consider is one in which wealth adjusts very fast relative to the price level. We consider the limiting case in which $\sigma_{1}=\infty$ while $\sigma_{2}=0$. Thus $b^{d}$ adjusts to keep wealth at its desired level. In this limiting case we allow the private sector to adjust its stock of foreign bonds discontinuously in response to a change in domestic asset supplies by running a large current account deficit or surplus. We no longer impose the initial condition $b^{d}(0)=0$. For simplicity, we assume that desired wealth is constant, so that $h=0$, throughout.

In considering this case we use equations (23) through (27) to solve for $b^{d}, c, r, y$, and $f$, setting $h=0$, as functions of $e$ and $p$, whose behaviour continues to be described by (28) and (29). Equation (30) no longer applies. The system may now be described by the following homogeneous pair of differential equations

$$
\left(\begin{array}{l}
\dot{x}_{1} \\
\dot{x}_{2}
\end{array}\right)=\left(\begin{array}{cc}
a_{1}^{\prime} & a_{2}^{\prime} \\
\theta & -\theta
\end{array}\right)\left(\begin{array}{l}
x_{1} \\
x_{2}
\end{array}\right)
$$

where $x_{1}$ and $x_{2}$ are again as before and now

$$
a_{1}^{\prime} \equiv \frac{\left(1-\mu_{2}\right)(1-\delta)}{\gamma \mu_{2}}+\frac{\alpha_{3} \rho+(1-\delta)}{\alpha_{1}} ; a_{2}^{\prime} \equiv \frac{\left(1-\mu_{2}\right) \delta}{\gamma \mu_{2}}-\frac{\alpha_{3} \rho-\delta}{\alpha_{1}} ; a_{0}^{\prime} \equiv\left[\frac{1-\mu_{2}}{\gamma \mu_{2}}+\frac{1}{\alpha_{1}}\right] \bar{m}
$$

The system can be solved exactly as before, with $a_{1}^{\prime}$ and $a_{2}^{\prime}$ replacing $a_{1}$ and $a_{2}$. Its solution can be written as

$$
e(t)=\bar{m}+A_{1}^{\prime} \exp \left(\lambda_{1}^{\prime} t\right)+A_{2}^{\prime} \exp \left(\lambda_{2}^{\prime} t\right)
$$




$$
p(t)=\bar{m}+A_{1}^{\prime}\left(\frac{\lambda_{1}^{\prime}-a_{1}^{\prime}}{a_{2}^{\prime}}\right) \exp \left(\lambda_{1}^{\prime} t\right)+A_{2}^{\prime}\left(\frac{\lambda_{2}^{\prime}-a_{1}^{\prime}}{a_{2}^{\prime}}\right) \exp \left(\lambda_{2}^{\prime} t\right)
$$

'where $\lambda_{1}^{\prime}$ and $\lambda_{2}^{\prime}$ are the characteristic roots of (45). Since

$$
a_{1}^{\prime}+a_{2}^{\prime}=\frac{1-\mu_{2}}{\gamma \mu_{2}}+\frac{1}{\alpha_{1}}>0
$$

there is again one negative and one positive root, which we identify as $\lambda_{1}<0$ and $\lambda_{2}>0$, respectively. This result applies to the net debtor as well as to the net creditor case, since $\mu_{2} \gamma>0$ in both cases, while $\mu_{2} \leqq 1$

Again we can use the condition for convergence and the initial condition (35a) to establish that

$$
\begin{gathered}
A_{1}^{\prime}=\frac{-a_{2}^{\prime}}{\lambda_{1}^{\prime}-a_{1}^{\prime}} \bar{m} \\
A_{2}^{\prime}=0
\end{gathered}
$$

Implying the solution

$$
\begin{gathered}
e(t)=\left[1+\frac{a_{2}^{\prime}}{a_{1}^{\prime}-\lambda_{1}^{\prime}} \exp \left(\lambda_{1}^{\prime} t\right)\right] \bar{m} \\
p(t)=\left[1-\exp \left(\lambda_{I}^{\prime} t\right)\right] \bar{m}
\end{gathered}
$$

Immediately following the increase in the supplies of money and bonds, the exchange rate is given by

$$
e(o t)=\left[1+\frac{a_{2}^{\prime}}{a_{1}^{\prime}-\lambda_{I}^{\prime}}\right] \overline{\mathrm{m}}
$$

As before $a_{1}^{\prime}-\lambda_{1}^{\prime}$ is positive so that $e(0+) \geqslant \dot{e}_{\text {. as }} a_{2}^{\prime}<0$, 1.e., as 


$$
\begin{gathered}
-32- \\
\gamma \mu_{2}\left(\delta-\alpha_{3} \rho\right)+\alpha_{1}\left(1-\mu_{2}\right) \delta \gtrless 0 .
\end{gathered}
$$

Again, when $\rho=0$ and $\gamma=\infty$, overshooting necessarily occurs. When wealth is maintained at a constant level, however, the result can be reversed only by an income effect $(\rho>0)$. In addition, differentiatIng (50) with respect to $\gamma$ yields an expression ambiguous in sign; Increasingly elastic speculation may raise or lower the impact effect on the exchange rate of a change in nominal asset supplies. When $\delta$ is near one, so that nontraded goods are the major component of the price Index, then increasingly elastic speculation will, as before, increase the degree of overshooting. The opposite occurs as $\delta$ approaches zero.

The reason for the different result from before is that, when the private sector can dishoard foreign bonds instantaneously, the exchange rate depreciation caused by the increase in the domestic asset supplies leads to a decrease in the real value of foreign bonds held by the public. The change is given by

$$
b^{d}(0+)+\delta e(0+)=\frac{1-\mu_{2}}{\mu_{2}}\left[\frac{a_{1}^{\prime}}{a_{1}^{\prime}-\lambda_{1}^{\prime}}(1-\delta)-\delta\right] \bar{m}
$$

which is always negative. Since the shock we consider now leads to a fall rather than to a rise in the real holdings of foreign assets, the forward exchange premium $f$ is increased. Our previous reasoning is reversed.

$$
\text { Since } e(0+)>0 \text {, while }(52) \text { is negative, } b^{d}(0+)<0 \text {. Thus }
$$
the effect of a proportional increase in domestic nominal assets is to create an initial balance of payments deficit, which is then offset by : a surplus as the nominal foreign bond supply is restored to its infial 
level. The rate of change in foreign bond holdings, and hence the current account, during the return to steady state is given by

$$
\dot{\mathrm{b}}^{\mathrm{d}}(t)=\frac{\lambda_{1}^{\prime}}{\mu_{2}\left(a_{1}^{\prime}-\lambda_{1}^{\prime}\right)}\left[\left(\mu_{2}-1\right)\left(\frac{\alpha_{3} \rho}{\alpha_{1}}+\frac{\delta}{\gamma}\right)-\frac{\mu_{2} \delta}{\alpha_{1}}+\delta \lambda_{1}^{\prime}\right] \mathrm{e}^{-\lambda_{1}^{\prime} t}
$$

which is always positive. Thus there will be a simultaneous exchange rate appreciation $(\dot{e}<0)$ and balance of payments surplus if overshoot-ing occurs on impact and simultaneous depreciation $(\dot{e}>0)$ and surplus in the event of undershooting.

In considering the extreme situations in which wealth adjusts infinitely slowly or infinitely fast to monetary shocks, we have shown how the presence of risk averse speculation can complicate considerably the exchange rate dynamics. In addition, our results for these special cases suggest some implications for intermediate situations in which the portfolio response is positive but less than infinite. First, even if real income is unaffected, an increase in the supply of nominal assets can lead to undershooting or overshooting. A reduction in speculators' risk aversion makes an overshooting response more likely, and as speculators become more risk neutral, overshooting is guaranteed. Secondly, an increase in the supply of nominal assets will create initially a balance of payments deficit. A balance of payments surplus will eventually emerge that restores the nominal level of foreign assets to its initial position.

IV. Exchange Rate Dynamics: Open Market Operation

In Section III we analyzed a change in nominal asset supplies that was neutral in the sense that generated proportional changes in the steady state domestic price level and exchange rate with no change 
In the steady state domestic interest rate. We now consider a once-andfor-all increase in the domestic money supply of $\bar{m}$ percent that is achieved by a purchase of domestic bonds. The percentage change in bond supplies required is given by

$$
\bar{a}=\frac{-\left(1-\mu_{1}-\mu_{2}\right)}{\mu_{1}} \bar{m}
$$

Starting from initial levels of zero, the percentage changes in the steady state exchange rate, price level, and forward premium are

$$
\begin{gathered}
\tilde{\mathrm{e}}=\tilde{\mathrm{p}}=\frac{\mu_{2}{ }^{\overline{\mathrm{m}}}}{\mu_{2} \gamma+\left(1-\mu_{2}\right) \alpha_{1}} \leqq \bar{m} \\
\tilde{\mathrm{f}}=\frac{-\left(1-\mu_{2}\right) \overline{\mathrm{m}}}{\mu_{2} \gamma+\left(1-\mu_{2}\right) \alpha_{1}} \leqq 0
\end{gathered}
$$

respectively, while domestic holdings of foreign bonds change by

$$
\bar{b}^{d}=\frac{\left(1-\mu_{2}\right) \gamma \bar{m}}{\mu_{2} \gamma+\left(1-\mu_{2}\right) \alpha_{1}}>0 .
$$

As our analysis in Section II indicated, only when speculators are risk neutral $(\gamma \rightarrow \infty)$ do the exchange rate and price level change in proportion to $\bar{m}$, and the interest rate remain unchanged. Otherwise, there is a less than proportional increase in $\tilde{e}$ and $\tilde{p}$, while $\tilde{f}$ falls. Note that as $\gamma$ rises, so does the steady state response of $b^{d}$ to the open market expansion.

The transition to the new steady state can again be described by the system (31), the only difference being that $a_{0}$ and $c_{0}$ are replaced by $a_{0}^{\prime \prime}=-\bar{m} / \alpha_{1}, c_{0}^{\prime \prime}=0$, respectively. The same boundary conditions on $p, e$, and $b^{d}$ apply. As before, an analytic solution in the general case proves to be intractable and instead we focus on a special case. 
In the first case considered in Section III in which asset adjustment is infinitely slow $\left(\sigma_{1}=\sigma_{2}=0\right)$, the new steady state is never reached. Hence we consider only the other polar case of very rapid asset adjustment $\left(\sigma_{1}=\infty, \sigma_{2}=0\right)$. The analysis proceeds as in Section III.2. Equation (45) continues to describe the dynamics of adjustment, with $a_{0}^{: \prime}$ replacing $a_{0}^{\prime}$, and can be solved as before.

Our criterion for the overshooting of the exchange rate in Section III.2 continues to apply. An interesting question emerges, however, concerning the effect on impact of the operation on the domestic holdings of foreign bonds, which is given by

$$
b^{d}(o+)=\frac{I-\delta-\mu_{2}}{\mu_{2}} \text { e (ot) } \text {. }
$$

This expression is ambiguous in sign. The open market operation can, on impact, create a current account surplus or deficit depending upon whether the share of traded goods in consumption exceeds or is exceeded by the share of foreign bonds in wealth.

The expression may also be smaller or larger than $\tilde{b}^{-d}$. Foreign bond holdings may overshoot their new steady state level, requiring a subsequent deficit. Conversely, they may undershoot, so that a surplus will always be maintained. Which takes place is independent of whether exchange rate overshooting occurs. Consequently, the variety of simultaneous dynamic adjustments of $e$ and $b^{d}$ is large.

We can also consider an open market operation in the form of a purchase of foreign bonds in exchange for domestic money. To increase the money supply by $\bar{m}$ percent, the authorities must purchase an amount 


$$
\tilde{b}^{d}=e(o+)+\frac{1-\mu_{1}-\mu_{2}}{\mu_{2}} \bar{m}
$$

of foreign bonds. In terms of logarithmic deviations from the initial equilibrium, the new steady state values of $e, p, f$, and $b^{d}$ are respectively

$$
\begin{gathered}
\tilde{e}=\tilde{p}=\left(\frac{\mu_{2} \gamma+\alpha_{1}\left(1-\mu_{1}-\mu_{2}\right)}{\mu_{2} \gamma+\alpha_{1}\left(1-\mu_{2}\right)}\right) \bar{m}<\bar{m} \\
\tilde{\mathbf{f}}=\frac{-\mu_{1} \bar{m}}{\mu_{2} \gamma+\alpha_{1}\left(1-\mu_{2}\right)}<0 \\
\tilde{b}^{d}=\frac{\mu_{1} \gamma \bar{m}}{\mu_{2} \gamma+\alpha_{1}\left(1-\mu_{2}\right)}>0
\end{gathered}
$$

Once again, only when speculators are risk neutral $(\gamma \rightarrow \infty)$ do the exchange rate and price level change in proportion to $\bar{m}$ and the interest rate remain unchanged. Comparing (57) with (54) note that when the open market operation is performed with foreign rather than domestic bonds, the effect on the exchange rate and price level is greater, while that on the interest rate is reduced.

For the case in which asset adjustment is very rapid $\left(\sigma_{1}=\infty\right.$, $\sigma_{2}=0$ ), the dynamic analysis of Section III.2 again applies. In the absence of income effects, overshooting of the exchange rate necessarily occurs. Since e is greater, while $a_{1}^{\prime}, a_{2}^{\prime}$ and $\lambda_{1}^{\prime}$ are as before, e(ot) is 1ncreased. Because the monetary authority has purchased foreign bonds from the public and the exchange rate depreciation on impact is greater, so is the inftial current account surplus induced by the operation. 


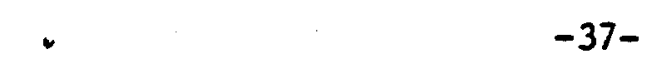

v. Conclusion

The assumption that speculative foreign exchange positions require a risk premium has implications for a number of propositions about open economies with flexible exchange rates. In particular, propositions about the impotence of fiscal policy and the equality in steady state between domestic and foreign interest rates based on the assumption of perfect capital mobility require the strong version of this assumption--uncovered interest rate parity--to hold. They do not obtain if only the weaker assumption of covered interest rate parity holds.

Furthermore, introducing risk aversion along with wealth effects in the demand for money has implications for exchange rate dynamics. It tends to reduce the presumption of overshooting of the exchange rate in response to monetary disturbances, both the likelihood that it happens at all and the amount by which it occurs if it does occur. To the extent that the major sources of disturbances are changes in nominal asset supplies, factors encouraging currency speculation, such as an increase in the number of speculators, are likely to reduce the overall risk aversion exhibited by the market and increase the volatility of the exchange rates. In this sense speculators destabilize the market. 


\section{Footnotes}

10ther authors draw the distinction between perfect capital mobility between countries and perfect substitutability between domestic and foreign bonds. The former term corresponds to the weaker definition of CIP, while the latter describes the strong definition of UIP: see Frankel (1981). Elsewhere, (Eaton and Turnovsky (1981)), we explore the implications of this distinction for the efficacy of policy and the international transmission of disturbances.

2

This result points to a deficiency with the assumption, at least as a basis for analyzing behaviourin steady state. As the size of a country's debt grows, so does its incentive to depreciate its currency (if debt is denominated in domestic currency) or to default. Either will lead to departures from UIP or CIP. Credit rationing could eliminate capital mobility at the margin altogether. An additional problem, of course, is that a small country running a perpetual deficit will eventually develop a debt that looms large in international capital markets, if its debt grows faster than the world economy. In this case its debt will have an impact on world interest rates.

3 Steady states possessing varying degrees of stationarity are familiar from the literature; see, e.g., Dornbusch (1976), Turnovsky (1977).

${ }^{4}$ This proposition is of course based on the presumption that the world is not characterized by conditions of secular inflation, an assump- tion made throughout this analysis. Under secularly inflationary conditions, the steady state relationship between the domestic and foreign interest rates under UIP is $R=R^{*}+e$, where $e$ is the secular rate of inflation. It is clear that through e domestic policies are able to influence the domestic nominal rate of interest even if UIP obtains.

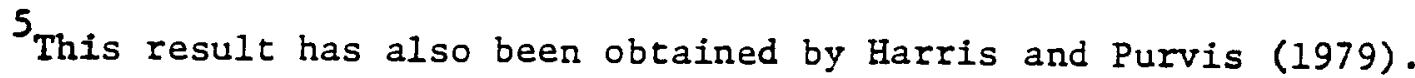

6

We stress that this statement refers to models based on similar assumptions to those we shall introduce. A good deal of attention has been devoted to the literature establishing the robustness of the overshooting phenomenon and many models in which it does not occur now exist. Dornbusch (1976) shows that introducing variable output can eliminate overshooting. Turnovsky (1981) shows that introducing imperfect substitutability between bonds and wealth effects can also eliminate the phenomenon in a model in which prices are assumed to be perfectly flexible. His analysis does not distinguish between imperfect substitutability arising from exchange risk (leading to departures from UIP) and from political risk (leadingto departures from CIP). Elsewhere (Eaton and Turnovsky (1981)) we show that each has potentially different implications for the response of the economy to a monetary shock. 
Tote also that we include real output, rather than real income in the money demand function. This allows us to ignore the effects of change in real income from foreign bonds on money demand. In the absence of any strong theoretical argument in favour of using real income rather than real output as a proxy for transaction demand, and in view of the simplicity that obtains when the latter is used, we have adopted this specification. See Dornbusch and Fischer (1980) for an alternative approach, although their analysis treats real income as fixed.

8

We find it analytically convenient to separate forward market participation into pure speculation and pure arbitrage. We implicitly treat the acquisition of an amount of uncovered foreign bonds as combining a covered investment of $\mathrm{x}$ in foreign bonds and a speculative purchase of foreign currency forward in amount $x$. In a portfolio model of foreign investment we identify a third motive for participating in the forward market as hedging against domestic inflation. Forward positions for hedging purposes depend upon the relative variability of the domestic and foreign price levels and do not respond to the variables we are concerned with here. Thus we may treat the forward position due to hedging as a constant absorbed in $J_{t}$; see Eaton and Turnovsky (1981).

9

The notion of a "risk premium" on forward exchange in a non-stochastic model is somewhat awkward, although no more so than having different rates of return on different securities as is commonplace in conventional deterministic macroeconomics. Our main reason for doing this is to preserve analytical tractability and also to enable us to preserve comparability with the existing literature, which is also deterministic. One interpretation of our approach is that while expectations are on average realized, nevertheless the returns are subject to risk, the magnitude of which will affect the function $\mathrm{J}$; see Eaton and Turnovsky (1981).

10

This form of price adjustment rule is specified by

$$
\dot{\mathbf{P}}=\omega(\mathrm{Y}-\overline{\mathrm{Y}})
$$

Equation (11) is then obtained by combining this equation with (10) to yield

$$
\dot{P}=\omega Z(E / P) \equiv G(E / P)
$$

${ }^{11}$ To see this, observe that with bond financing the dynamics of $E, P$ involve only equations (7), (3), (8), (10) and (11). With a moneyfinanced deficit equation (12), with $A \equiv 0$, must be considered as 
well. The fact that bond accumulation may continue in steady state in the absence of wealth effects in relevant demand functions is familiar from the simple IS-LM model; see, e.g., Turnovsky (1977, Chapter 4).

12 Another policy worth noting is the balanced budget. As long as $\mathrm{H}$ enters the money demand function, steady state always requires $g=b=0$; irrespective of the elasticity of the speculative demand for forward exchange with respect to the risk premium. The same applies if $L$ is independent of $\mathrm{H}$, as long as $\mathrm{J}^{\mathrm{P}}$ is finite. The limiting case of infinitely elastic speculation, steady state requires only that $g=0$.

13 This type of specification is used, for example, by Tobin and Buiter (1976) for a closed economy.

14

Even in this limiting case, propositions (iii) and (iv) do not necessarily hold under alternative, plausible specifications of asset supply and asset accumulation behaviour. Consider the case in which taxes are maintained at a constant level in real terms. If the government deficit is bond-financed and if the demand for money is independent of $\mathrm{H}$ propositions (iii) and (iv) do still hold. However, if the deficit is money-financed an increase in the stock of comestic bonds causes a proportionate change in $E$, which tinrough the deficit leads to an eventual proportionate change in $M$. This contradicts proposition (iv), while the causality of (iii) is reversed. With a balanced budget the exchange rate is homogeneous of degree one in money and. domestic bonds.

15

For the case in which the country we are considering is a net debtor in terms of foreign currency denominated bonds, $b \mathrm{~d}$ should be interpreted as the logarithm deviation of this country's debt from its steady state level. The term $\mu_{2}$ will then be a negative number, where $-H_{2}$ is the logarithm of the net foreign currency denominated debt.

${ }^{16}$ When the country we are considering is a net debtor in foreign currency denominated bonds, then bd should be interpreted as in footnote 15. The right hand side of (28) should then be reversed in sign.

17

This speculation deviates slightly from that adopted by Dornbusch et al., In which prices are assumed to adjust in proportion to excess demand, as a result of which the domestic interest rate appears in (29) as well. We have chosen our specification not only for reasons of its simplicity, but also because it follows directly from a model based on long-term contracts.

18 In interpreting this inftial steady state in which all variables equal zero $1 t$ should be recalled that all variables are measured in deviarion form. 
${ }^{19}$ This statement applies whether the country is a net creditor or a net debtor.

20

Convergence may follow by appealing to transversality conditions from appropriate optimizing models which, provided that the underlying utility function satisfies suitable restrictions, ensure that price movements remain bounded.

21 Buiter and Miller (1981) also develop a third-order system to model exchange rate dynamics. They can obtain explicit solutions for only numerical examples, however.

22 Even when the country is a net debtor $\left(\mu_{2}<0\right)$, a positive and negative eigenvalue will obtain except for extremely high values of $\alpha_{2}$ and $-\mu_{2}$.

23 If we consider a net debtor, the role of speculation in determining the impact response of the exchange rate is much more complicated. Its analysis is left as an exercise for the interested reader.

${ }^{24}$ On the other hand, $\mathrm{d}\left|\lambda_{1}\right| / \mathrm{d} \gamma>0$ as well; a reduction in the risk aversion of speculators increases the speed with which the exchange rate and domestic price level attain their new equilibrium values. 


\section{References}

Adler, M. and B. Dumas (1977), "The Microeconomics of the Firm in an Open Economy," American Economic Review, Papers and Proceedings, (February) 67, 1977, 180-189.

Aliber, R. 2. (1973), "The Interest Rate Parity Theorem: A Reinterpretation," Joumal of Political Economy, (November/December) 81, 1451-1459.

Bilson, J. F. O. (1978), "Rational Expectations and the Exchange Rate," in J. A. Frenkel and H. G. Johnson eds., The Economics of Exchange Rates, Addison-Wesley, Reading, Mass.

Buiter, W. H. and M. Miller (1981), "Real Exchange Rate Overshooting and the Output Cost of Bringing Down Inflation," NBER Working Paper No. 749 (September).

Dornbusch, R. (1976), "Exchange Rate Expectations and Monetary Policy," Joumal of Political Economy, (December) 84, 1161-1176.

Dornbusch, R. and S. Fischer (1980), "Exchange Rates and the Current Account," American Econontic Review, (December) 70, 960-971.

Driskill, R. (1980), "Exchange Rate Dynamics, Portfolio Balance, and Relative Prices," American Economic Review, (September) 70, 776-783.

Eaton, J. and S. J. Turnovsky (1981), "Exchange Risk, Political Risk - and Macroeconomic Equilibrium," Economic Growth Center Discussion Paper No. 388 (forthcoming American Economic Review).

Fleming, J. M. (1962), "Domestic Financial Policies under Fixed and Floating Exchange Rates," IMF Staff Papers, (November) 9, 369-379.

Frankel, J. A. (1982), "The Diversifiability of Exchange Risk," Joumal of Intermational Economics 9, 379-393.

Frankel, J. A., "Monetary and Portfolio-Balance Models of Exchange Rate Determination," in J. Bhandari and B. Putnam (eds.), The International Transmission of Economic Disturbances under Flexible Exchange Rates, MIT Press, Cambridge, Mass.

Frenkel, J. A. and R. M. Levich (1975) "Covered Interest Arbitrage: Exploited Profits?" Joumal of Political Economy 83, 325-338.

Frenkel, J. A. and R. M. Levich (1975) "Transactions Costs and Interest Arbitrage: Tranquil Versus Turbulent Periods," Joumal of Political Economy, (April) 85.

Gray, M. R. and S. J. Turnovsky (1979) "The Stability of Exchange Rate Dynamics under Perfect Myopic Foresight," International Economic Review, (October) 20, 643-660. 
Hansen, L. P. and R. J. Hodrick (1980) "Forward Exchange Rates as Optimal Predictors of Future Spot Rates," Jcumal of Political Economy, (October) 88, 829-853.

Harris, R. G. and D. D. Purvis (1979) "Equilibrium Theories of the Forward Exchange Rate," Institute for Economic Research Discussion Paper \#354, Queen's University.

Kouri, P. J. K. (1976) "The Determinants of the Forward Premium," Institute for International Economic Studies Paper No. 62, University of Stockholm, August.

Levich, R. (1978) "Tests of Forecasting Models and Market Efficiency in the International Money Market," in J. A. Frenkel and H. G. Johnson, eds., The Economics of Exchange Rates, Addison-Wesley, Reading, Mass.

Mundel1, R. A. (1963) "Capital Mobility and Stabilization Policy Under Fixed and Flexible Exchange Rates," Canadican Joumal of Economics and Political Science, (November) 29, 475-485.

Solnik, B. (1973) European Capital Markets, D. C. Heath, Lexington, Mass.

Tobin, J. and W. Buiter (1976) "Long-run Effects of Fiscal and Monetary Policy on Aggregate Demand," in J. L.Stein (ed.) Monetarism, North-Holland, Amsterdam.

Turnovsky, S. J. (1977) Macroeconomic Analysis and Stabilization Policy, Cambridge University Press, Cambridge, U.K.

Turnovsky, S. J. (1981) "The Asset Market Approach to Exchange Rate Determination: Some Short-Run Stability, and Steady State Properties," Joumal of Macroeconomics, (Spring) 3, 1-32.

Wilson, C. (1979) "Anticipated Shocks and Exchange Rate Dynamics," Joumal of Political Economy 87, 639-647. 